\title{
Therapeutic strategies for alcoholic liver disease: Focusing on inflammation and fibrosis (Review)
}

\author{
HIDETO KAWARATANI $^{1}$, KEI MORIYA ${ }^{1}$, TADASHI NAMISAKI ${ }^{1}$, MASAKAZU UEJIMA ${ }^{1}$, \\ MITSUTERU KITADE ${ }^{1}$, KOUSUKE TAKEDA ${ }^{1}$, YASUSHI OKURA ${ }^{2}$, KOUSUKE KAJI ${ }^{1}$, HIROAKI TAKAYA ${ }^{1}$, \\ NORIHISA NISHIMURA ${ }^{1}$, SHINYA SATO ${ }^{1}$, YASUHIKO SAWADA ${ }^{1}$, KENICHIRO SEKI ${ }^{1}$, TAKUYA KUBO ${ }^{1}$, \\ AKIRA MITORO $^{1}$, JUNICHI YAMAO ${ }^{2}$ and HITOSHI YOSHIJI ${ }^{1}$ \\ ${ }^{1}$ The Third Department of Internal Medicine and ${ }^{2}$ Department of Endoscopy and Ultrasound, \\ Nara Medical University, Kashihara, Nara 634-8522, Japan
}

Received November 14, 2016; Accepted March 30, 2017

DOI: $10.3892 / \mathrm{ijmm} .2017 .3015$

\begin{abstract}
Excessive alcohol consumption is the most common cause of liver disease in the world. Chronic alcohol abuse leads to liver damage, liver inflammation, fibrosis and hepatocellular carcinoma. Inflammatory cytokines, such as tumor necrosis factor- $\alpha$ and interferon- $\gamma$, induce liver injury, which leads to the development of alcoholic liver disease (ALD). Hepatoprotective cytokines, such as interleukin (IL)-6 and IL-10, are also associated with ALD. IL-6 improves ALD via the activation of STAT3 and the subsequent induction of a variety of hepatoprotective genes in hepatocytes. Alcohol consumption promotes liver inflammation by increasing the translocation of gut-derived endotoxins to the portal circulation and by activating Kupffer cells through the lipopolysaccharide/Toll-like receptor 4 pathways. Oxidative stress and microflora products are also associated with ALD. Hepatic stellate cells play an important role in angiogenesis and liver fibrosis. Anti-angiogenic therapy has been found to be effective in the prevention of fibrosis. This suggests that blocking angiogenesis could be a promising therapeutic option for patients with advanced fibrosis. This review discusses the main pathways associated with liver inflammation and liver fibrosis as well as new therapeutic strategies.
\end{abstract}

\section{Contents}

1. Introduction

2. Metabolism of alcohol

Correspondence to: Dr Hideto Kawaratani, The Third Department of Internal Medicine, Nara Medical University, Kashihara, Nara 634-8522, Japan

E-mail: kawara@naramed-u.ac.jp

Key words: alcoholic liver disease, hepatic stellate cells, liver inflammation, liver fibrosis, tumor necrosis factor- $\alpha$, transforming growth factor- $\beta$
3. Cytokines

4. Chemokines and inflammasomes

5. Toll-like receptors

6. Gut-derived bacteria

7. Angiogenesis

8. Fibrosis

9. Treatment for ALD

10. Future therapies for ALD

11. Conclusion

\section{Introduction}

It is known that alcohol-related liver disease is a major cause of morbidity and mortality worldwide. Chronic alcohol abuse leads to liver damage, simple steatosis, alcoholic liver disease (ALD) and alcoholic steatohepatitis (ASH) and sometimes leads to liver cirrhosis or hepatocellular carcinoma (HCC). Although most heavy drinkers develop steatosis, 10 to $20 \%$ of those with steatosis progress to ASH and develop cirrhosis $(1,2)$. Steatosis is usually asymptomic and is rapidly reversible with abstinence (2). However, continuous alcohol abuse in some patients leads to liver inflammation characterized by the infiltration of polymorphonuclear leukocytes. Hepatocyte damage often described as ballooning or Mallory bodies is characteristic of ASH. Twenty to forty percent of the patients develop liver fibrosis, and 10 to $20 \%$ of patients develop cirrhosis with various complications, such as ascites, variceal bleeding and hepatic encephalopathy (Fig. 1) $(3,4)$. The prognosis of ALD is poor, especially in liver cirrhosis (5) or HCC (6). The pathogenesis of ALD is not fully understood, but some factors, such as the metabolism of alcohol into toxic products, oxidative stress, acetaldehyde adducts, abnormal methionine metabolism, malnutrition, endotoxin activation, and impaired hepatic regeneration, are involved (7). Kupffer cells, macrophages residing in the liver, play a role in the innate immune system and produce various cytokines, which may lead to liver disease (8). Tumor necrosis factor- $\alpha$ (TNF- $\alpha)$ is mainly involved in acute alcoholic liver injury (9). By drinking alcohol, the permeability of the intestinal membrane is augmented 
and the portal blood endotoxin [lipopolysaccharide (LPS)] concentration continuously increases (10). The Kupfer cells are activated by phagocytozing apoptotic cells, which increases their inflammatory cytokine production (11). Chronic alcohol abuse leads to hepatocyte injury by TNF- $\alpha$ after phagocytosis by Kupffer cells. Alcohol consumption promotes hepatic inflammation by increasing the translocation of gut-derived endotoxins and activating Kupffer cells through Toll-like receptor 4 (TLR4) signaling. ALD is associated with imbalanced immune responses and increased production of proinflammatory cytokines or chemokines (12). Hepatoprotective cytokines, such as interleukin-6 (IL-6), and anti-inflammatory cytokines, such as IL-10, protect against the development of ALD (13). In contrast, hepatic stellate cells (HSCs) are the main source of transforming growth factor- $\beta$ (TGF- $\beta$ ) which is associated with liver fibrosis. Liver fibrosis can be defined as a result of progressive accumulation and decreased remodeling of the extracellular matrix (ECM). ECM remodeling is the main source of homeostasis during liver fibrosis. This review mainly discusses the molecular mechanisms associated with liver inflammation and liver fibrosis that may represent future therapeutic targets.

\section{Metabolism of alcohol}

When alcohol is consumed, it passes from the stomach and intestine into the blood by the process of absorption. Next, alcohol enters into the liver through the portal vein. The mechanism of alcohol metabolism is shown in Fig. 1. In brief, in the liver, alcohol dehydrogenase (ADH), the main enzyme in alcohol metabolism (14), mediates the development of alcohol to acetaldehyde. Acetaldehyde is rapidly converted to acetate by acetaldehyde dehydrogenase and is eventually metabolized to carbon dioxide and water in muscle tissues. The microsomal ethanol oxidizing system is another pathway of alcohol metabolism, which is independent of ADH (15). Alcohol is metabolized in the liver by the enzyme cytochrome P450 2E1 (CYP2E1), which is mainly expressed in the liver. CYP2E1 is mainly located within the endoplasmic reticulum, but it is also expressed in mitochondria (16), and its expression is increased after chronic alcohol consumption (17), with an increase in acetaldehyde. Acetaldehyde has a stronger toxicity than ethanol and can lead to liver injury. Most of the alcohol consumed is metabolized in the liver, but the small quantity that remains unmetabolized is excreted in breath and urine (Fig. 2).

\section{Cytokines}

$T N F-\alpha$. TNF- $\alpha$ is a cytokine involved in systemic inflammation and is a member of a cytokine family that stimulates acute inflammation. TNF- $\alpha$ is mainly produced by Kupffer cells in the liver and is also an important mediator of inflammation, cell proliferation and apoptosis (9). TNF- $\alpha$ functions as a critical inflammatory cytokine in the progression of ALD (4). However, the mechanism of the enhancing effect of alcohol on TNF- $\alpha$ has not yet been clarified. Kupffer cells secrete inflammatory cytokines (18) and reactive oxygen species (19), which activate hepatocytes, HSCs and endothelial cells (20). In alcoholic hepatitis (AH), inflammatory cytokines, such as TNF- $\alpha$, IL-6, IL-8 and IL-18 induce liver injury (21). Serum

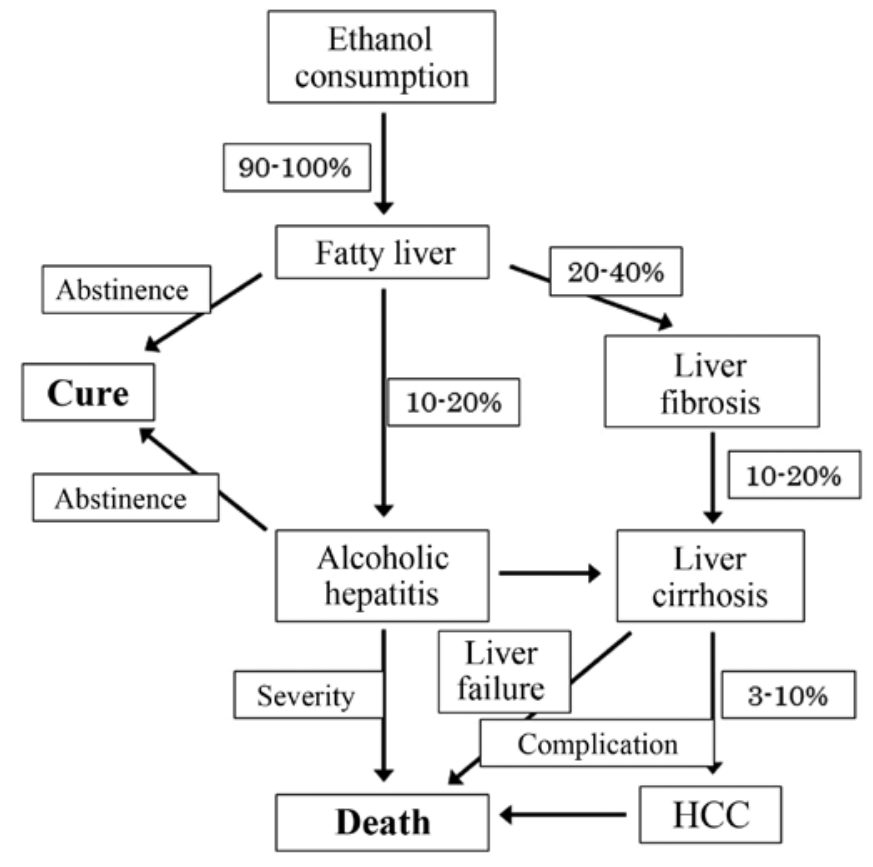

Figure 1. The natural history of alcoholics. HCC, hepatocellular carcinoma.

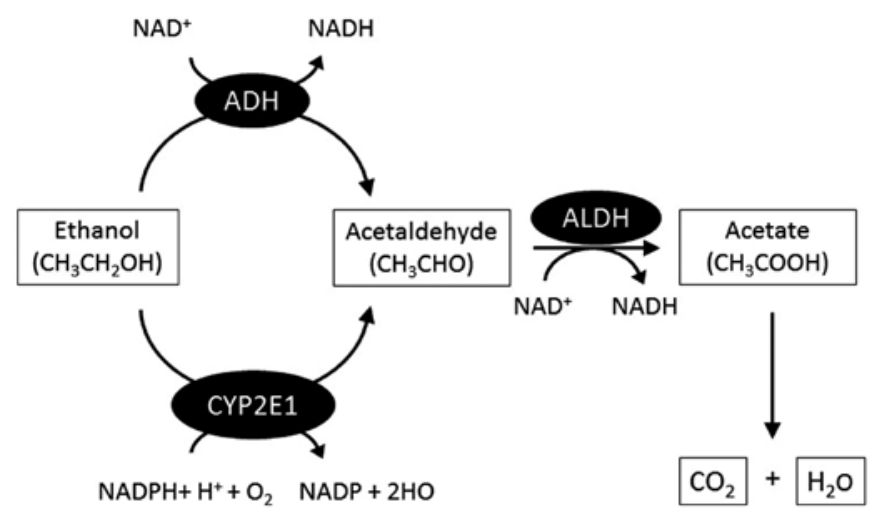

Figure 2. Metabolism of alcohol. ADH, alcohol dehydrogenase; ALDH, aldehyde dehydrogenase; CYP2E1, Cytochrome P450 2E1.

TNF- $\alpha$ is increased in patients with ALD and correlates with mortality. After chronic alcohol consumption, Kupffer cells exhibit enhanced sensitivity to LPS-stimulated TNF- $\alpha$ production (22). Administration of excessive ethanol to TNF- $\alpha$-knockout mice does not result in liver injury, and in both ALD and non-alcoholic steatohepatitis (NASH) (23), TNF- $\alpha$ is responsible for the development of liver injury. Treatment with pentoxifylline, an inhibitor of TNF- $\alpha$, was found to improve the survival of patients with severe $\mathrm{AH}$ (24). Anti-TNF- $\alpha$ antibodies were found to prevent inflammation and necrosis in an alcohol-fed rat model (25), and infliximab, an anti-TNF- $\alpha$ antibody, was also effective in patients with severe AH (26). The multiple cytokine modulator, Y-40138, inhibits the production of inflammatory cytokines, such as TNF- $\alpha$ or IL-6, and enhances anti-inflammatory cytokine production, such as IL-10. Our experimental research showed that Y-40138 reduced the production of inflammatory cytokines in ALD (27). These facts suggest that TNF- $\alpha$ plays an important role in the progression of ALD. 
$I L-6$ and $I L-10$. The role of IL-6 in ALD is complex and is not well understood. IL-6 appears to have some beneficial effects on the liver by possibly protecting against hepatocyte apoptosis and participating in mitochondrial DNA repair following alcoholic liver injury (28). IL-10 is an anti-inflammatory cytokine that controls the endogenous production of TNF- $\alpha$ during endotoxemia and reduces LPS stimulation when added exogenously (29). The liver is the main organ of IL-10 production (30), and Kupffer cells and lymphocytes are the main producers of IL-10. IL-10 is stimulated by LPS and downregulates the release of TNF- $\alpha$ and IL-6. IL-10 also exerts a hepatoprotective effect on liver proliferation and fibrosis (31). IL-6 may promote human Th17 cell differentiation and IL-17 production. Therefore, IL-6 contributes to ethanol-induced liver inflammation. After alcohol consumption, IL-6 is released along with IL-10, TNF- $\alpha$ and other cytokines by Kupffer cells. Both IL- 6 and IL-10 play roles in reducing alcoholic liver injury and inflammation through the activation of signal transducer and activator of transcription 3 (STAT3) (13). IL-6 is elevated in chronically alcohol-fed animals and in alcoholics (32). In contrast, IL-6-knockout chronically alcohol-fed mice were found to have increased liver fat accumulation, lipid peroxidation, mitochondrial DNA damage, and sensitization of hepatocytes to TNF- $\alpha$-induced apoptosis $(28,33)$. Blocking of IL-6 and IL-10 signaling in the mice reduced neutrophil and mononuclear cell infiltration and inflammation (34). IL-10 decreases the production of TNF- $\alpha$, IL-1 $\beta$ and IL- 6 from activated Kupffer cells and monocytes. IL-10-deficient mice exhibited increased liver inflammation after being fed ethanol (35). IL-10-knockout mice have elevated IL-6 and STAT3 activation in the liver, leading to steatosis and hepatocellular damage. These findings suggest that both IL-6 and IL-10 have a protective effect in the early phase of ALD. On the other hand, IL-10-knockout mice exhibit reduced fatty liver change and lower serum aspartate aminotransferase and alanine transaminase levels after ethanol feeding than wild-type mice (35). Recently, it has been suggested that IL-10 may play a biphasic role. First, IL-10 inhibits inflammatory cytokines (LPS, TNF- $\alpha$, IL-6), reducing steatosis and liver damage; second, IL-10 blocks IL-6 production, enhancing liver damage. The overall effect of IL-10 on hepatic steatosis or liver injury may be determined by the balance between proinflammatory cytokines that promote liver injury and hepatoprotective cytokines that prevent liver injury.

Other cytokines. Nuclear regulatory factor- $\kappa \mathrm{B}(\mathrm{NF}-\kappa \mathrm{B})$ is a protein complex that controls the transcription of DNA and is a central regulator of cellular stress in all liver cell types. $\mathrm{NF}-\kappa \mathrm{B}$ plays a key role in regulating the immune response to infection and acute and chronic inflammation. Activation of $\mathrm{NF}-\kappa \mathrm{B}$ in rats can induce IL- $1 \beta$ expression, which increases the expression of proinflammatory molecules (36). IL-1 $\beta$ and IL-6 appear essential for the induction of Th17 lymphocyte differentiation from human naive $\mathrm{CD}^{+}{ }^{+} \mathrm{T}$ cells (37). Furthermore, LPS-stimulated human monocytes induce Th17 polarization of naive $\mathrm{CD}^{+}{ }^{+} \mathrm{T}$ cells in an IL- $1 \beta$ signaling-dependent manner. IL-8 is produced by macrophages and is a critical proinflammatory cytokine involved in the mobilization of neutrophils. IL- 8 is induced by TNF- $\beta$ and TLRs via the activation of $\mathrm{NF}-\kappa \mathrm{B}$. Serum IL-8 is highly elevated in patients with $\mathrm{AH}$ and is linked to infiltration with neutrophils. However, IL-8 is only moderately elevated in alcoholic cirrhosis patients and alcoholics. IL-17 is a cytokine that acts as a potent mediator in delayed-type reactions by increasing chemokine production in various tissues to recruit monocytes and neutrophils to the inflammation site and activate NF- $\mathrm{NB}$ or induce IL-8. IL-17 plays a key role in autoimmune diseases (38). IL-17 stimulates multiple types of non-parenchymal hepatic cells to produce proinflammatory cytokines and chemokines such as TNF- $\beta$ (39). Plasma IL-17 levels are higher in patients with ALD than those in controls (40). The functions of Th17 cells are also mediated via IL-22, a member of the IL-10 family, playing an important role in promoting hepatocyte survival and proliferation (41). IL-22 administration to alcohol-fed mice also prevented liver steatosis and liver injury through the activation of hepatic STAT3 (42).

\section{Chemokines and inflammasomes}

Members of the CXC family of chemokines include IL-8 and growth-regulated $\alpha$-protein (Gro- $\alpha$ ). These mediators attract polymorphonuclear leukocytes, which are predominant inflammatory cells infiltrating the livers of patients with ALD. In patients with $\mathrm{AH}$, expression of these chemokines in the liver correlates with the severity of portal hypertension and patient survival (43). CCL2 [monocyte chemoattractant peptide-1 (MCP-1)] is a member of the $\mathrm{CC}$ chemokine family. Its expression can be induced by inflammatory cells, hepatocytes and HSCs. CCR2 is the only known receptor for CCL2 and is expressed on monocytes, T lymphocytes and basophils (44). MCP-1 regulates adhesion molecules and proinflammatory cytokines, such as TNF- $\alpha$, IL- $1 \beta$ and IL-6 (45). The pivotal role of MCP-1 in ALD was recognized by observing higher amounts of MCP-1 than those of other $\mathrm{CC}$ chemokines and macrophage inflammatory protein-1 $\alpha$ in the liver and mononuclear cells in patients with $\mathrm{AH}(46)$. MCP-1 is important in the modulation of proinflammatory cytokines (47). Blockage of MCP-1 protects mice against ALD, independently of CCR2, by inhibiting proinflammatory cytokines and induction of fatty acid oxidation, linking chemokines to hepatic lipid metabolism (48). In the liver, HSCs express a large number of chemokines (49), including CXC chemokines (CXCL8, CXCL9, CXCL10 and CXCL12) and CC chemokines (CCL2, CCL3 and CCL5) (49). These chemokines have been related to liver fibrosis in chronic liver diseases (49,50). CXC chemokines drive angiogenesis during fibrosis initiation and progression $(49,50)$.

The inflammasome is a multiprotein oligomer consisting of caspase-1, an apoptosis-associated speck-like protein containing caspase recruitment domain, and NOD-like receptor family pyrin domain-containing 3 (NLRP3) that mediate the response to cellular danger signals activating and recruiting inflammatory cells (51). IL-1 $\beta$ is produced following inflammasome activation. NLRP3 activates inflammatory caspase, caspase-1, which accelerates the aging process through the impairment of autophagy, leading to cell death.

Inflammasomes are activated by two steps. The first step is upregulation of pro-IL-1 $\beta$ expression and inflammasome components. The second step is triggered by ligands of the NLR sensor in the inflammasome, resulting in cleavage of 


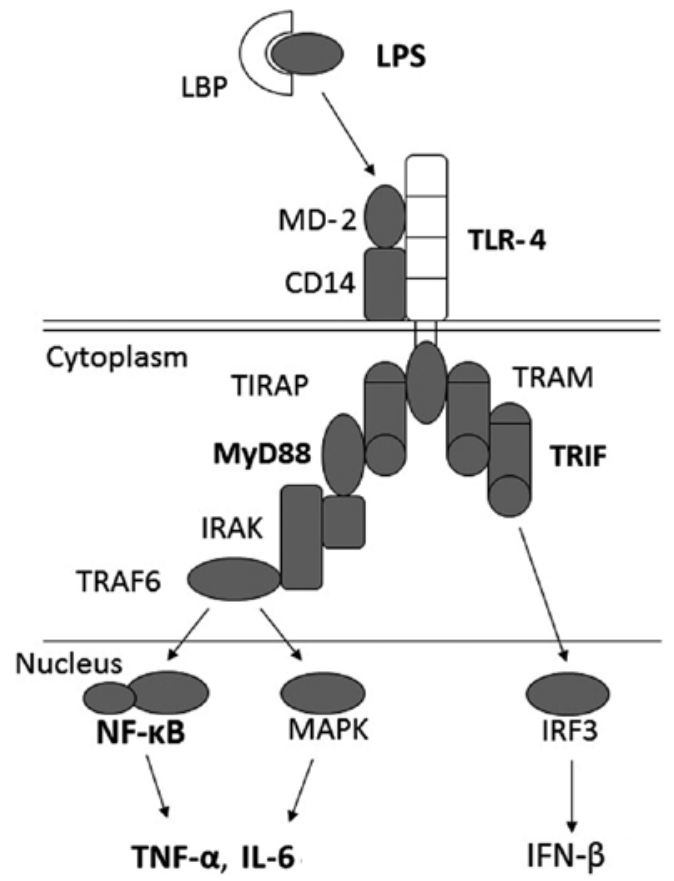

Figure 3. Toll-like receptor 4 (TLR4) signaling pathway. LPS, lipopolysaccharide; MyD88, myeloid differentiation primary response 88 ; NF- $\mathrm{kB}$, nuclear factor- $\mathrm{\kappa}$.

procaspase-1 into active caspase-1 that cleaves pro-IL-1 $\beta$ into the mature, secreted IL-1 $\beta$ (52). Increased IL-1 $\beta$ upregulates caspase-1 activity and inflammasome activation. Alcohol results in release of sterile danger signals, uric acid, and extracellular adenosine triphosphate, which are activators of the NLRP3 inflammasome (53). Inflammasomes are activated in bone marrow (BM)-derived Kupffer cells in alcohol-fed mice through IL-1 signaling (54). IL-1 $\beta$ increases the activity of MCP-1 in hepatocytes and contributes to increased TLR4dependent proinflammatory signaling in macrophages.

\section{Toll-like receptors}

TLRs comprise a family of pattern-recognition receptors, which contribute to the production of antimicrobial peptides against microorganism invasion. Endogenous components derived from dying host cells, termed damage-associated molecular patterns (DAMPs), can also activate TLRs (55). To date, 11 and 13 TLRs have been identified in humans and mice, respectively (56). TLRs recognize pathogen-derived molecules, such as structural components unique to bacteria, virus, parasites, and fungi and activate inflammatory cytokines and type I interferon (IFN) production. TLRs are expressed on the surface of immune cells, such as macrophages, dendritic cells and epithelial cells. After binding to its ligands, TLRs transduce signals via myeloid differentiation factor 88 (MyD88). TLR4 is expressed on the surface of Kupffer cells and various other types of cells that transmit endotoxin signals. LPS is the ligand of TLR4, and cluster of differentiation 14 (CD14), a component of the innate immune system, binds LPS and subsequently presents it to TLR4 and MD-2, which activate MyD88. This leads to the activation of NF- $\kappa B$ (57) and results in the production of various proinflammatory cytokines, such

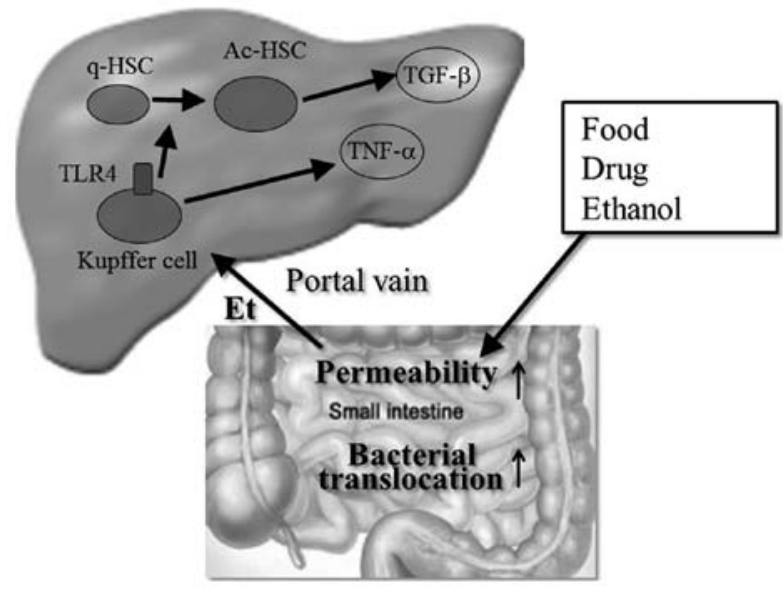

Figure 4. Interaction between the small intestine and liver. q-HSC, quiescent hepatic stellate cell; Ac-HSC, activated hepatic stellate cell.

as TNF- $\alpha$ and IL-6. Both MyD88 and TRIF (MyD88-independent) signaling modulate TLR4 (Fig. 3). Mice deficient in TLR4 expression are protected from alcohol-induced liver inflammation and hepatocyte injury (58). In the liver, TLR4 is expressed not only on innate immune cells, such as Kupffer cells, but also on hepatocytes, HSCs, sinusoidal endothelial cells, and biliary epithelial cells. The TLR4-TRIF-dependent pathway is important in the development of ASH (59). Blocking of TLR4 or CD14 reduced liver pathology and inflammation in a mouse model of alcoholic liver injury $(60,61)$. LPS recognition by TLR4 expressed on HSCs and sinusoidal epithelial cells also contribute to the progression of ALD (61). Alcohol stimulates Kupffer cells and monocytes to produce increased TNF- $\alpha$ in response to endotoxins (62). Our group showed that endotoxemia plays an important role in the initiation and aggravation of ALD through the enhancement of proinflammatory cytokines, including IL-6, IL-8 and TNF- $\alpha(63,64)$. Hepatic expression of TLR1, 2, 4, 6, 7, 8 and 9 mRNA was increased in chronically alcohol-fed mice (65). Alcohol feeding also resulted in sensitization to liver damage and inflammation because administration of TLR1, 2, 4, 6, 7, 8 and 9 ligands resulted in increased expression of TNF- $\alpha$ mRNA (66). Acute alcohol exposure inhibited TLR4 signaling in macrophages following alcohol treatment in mice, leading to decreased LPS-induced TNF- $\alpha$ production. It is clear that alcohol abuse leads to the activation of innate immunity via TLR signaling. This suggests that TLRs are important in ALD.

\section{Gut-derived bacteria}

Recently, the importance of bacterial translocation in the pathogenesis of ALD has been shown in many studies (67). Dysfunction of intestinal tight junctions $(68,69)$ or bacterial proliferation (70) by alcohol or its metabolites enhance bacterial translocation into the liver, which induces the activation of Kupffer cells to release various proinflammatory cytokines and chemokines (71) (Fig. 4). Chronic alcohol feeding causes structural changes in the gastrointestinal tract that may contribute to LPS translocation (72) and results in intestinal bacterial overgrowth and enteric dysbiosis, which is due to alcohol-induced downregulation of several 
intestinal antimicrobial molecules (73). ALD also results in quantitative alterations in intestinal microbiota. Small intestinal bacterial overgrowth is another cause of bacterial translocation. Chronic alcohol consumption elevates the growth of Gram-negative bacteria causing a decrease in both Bacteroidetes and Firmicutes and an increase in Actinobacteria and Proteobacteria (74). In chronic alcohol consumption, the intestinal flora releases a larger amount of endotoxins due to hyperpermeability, which is responsible for the altered intestinal barrier and activation of inflammatory processes, leading to the progression of ALD (75), cirrhosis and HCC (76). In the intestine, the disruption of tight junctions may lead to increased permeability to pathogens, which is a common mechanism involved in the pathogenesis of ALD (77). Zonula occludens-1 (ZO-1), occludin and claudin- 4 are transmembrane proteins expressed at tight junctions. Alcohol-treated mice showed loss of ZO-1, occludin, and claudin-4 expression in the colon. Alcohol-induced 'leaky gut' results in the translocation of Gram-negative bacteria from the intestinal lumen into the portal blood, elevating LPS levels and triggering significant inflammation and liver injury (78), and activation of Kupffer cells is involved in the pathogenesis of ALD (79). Treatment with antibiotics also prevents alcohol-induced liver injury (80). Probiotics modulate intestinal microbiota, which leads to decreased bacterial translocation and endotoxin production. Moreover, probiotics improve the intestinal barrier integrity, thereby improving ALD. These factors imply that there are interactions between the liver and intestinal bacteria in ALD.

\section{Angiogenesis}

Angiogenesis is an active, growth factor-dependent, and hypoxiainduced event that takes place in several organs during growth and repair of injured tissues $(81,82)$. Chronic ethanol consumption induces inflammation in the liver parenchyma, triggering both fibrogenesis and angiogenesis (83). Angiogenesis mainly contributes to the development of liver complications such as portal hypertension and formation of portal-systemic collaterals. Moreover, angiogenesis contributes to the progression of fibrosis in chronic liver disease. In contrast, intrahepatic vascular remodeling with capillarization of sinusoids and alcohol-related central zone steatosis of lobuli alter hepatic oxygen supply leading to hypoxia with formation of new vessels; thus, creating a viscous circle $(84,85)$. It has been suggested that angiogenesis may contribute to the progression of fibrosis during the wound healing process in chronic liver damage $(84,86)$. Moreover, wound healing is also defined by an increase in the expression of several cytokines and growth factors with pro-angiogenic action $(84,87,88)$. HSCs may constitute a crossroad at the interaction between inflammation, angiogenesis and fibrosis. Hepatic angiogenesis takes place in chronic liver diseases that are characterized by inflammation and progressive fibrosis. Anti-angiogenic therapy is efficient in the prevention of fibrosis in chronic liver diseases. Angiogenesis is activated by hypoxia and mediated by hypoxia-inducible factors (HIFs) $(87,88)$. HIFs are heterodimers formed by an oxygen-sensitive and inducible $\alpha$ subunit and an oxygen-independent $\beta$ subunit (87). HIF-1 $\alpha$, HIF- $2 \alpha$, and HIF-3 $\alpha$ have been described, and all bind to a common $\beta$ subunit named the aryl hydrocarbon nuclear receptor translocator. Vascular endothelial growth factor (VEGF)

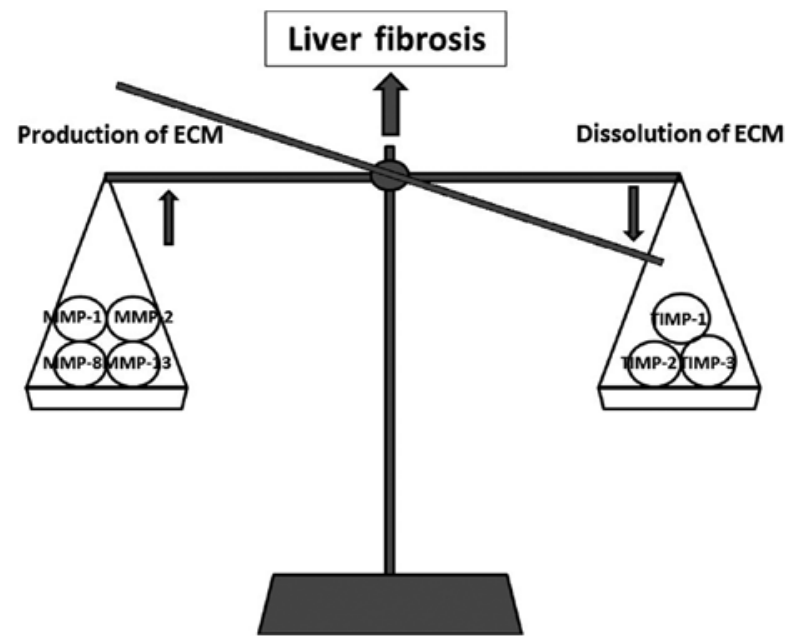

Figure 5. The balance of extracellular matrix (ECM) production and dissolution. MMP, matrix metalloproteinase; TIMP, tissue inhibitors of matrix metalloproteinase.

is the most potent stimulator of pathological angiogenesis and wound healing. It also induces vascular permeability inside injured tissues. VEGF is released under hypoxic conditions and regulated by HIF-1 $\alpha$. Chronic ethanol consumption is related to angiogenesis by means of finely coordinated action of various mediators in the liver (89). Ethanol upregulates VEGF and VEGF receptor-2 and stimulates angiogenesis in the rat liver (89). Tyrosine kinase receptors (Tie1 and Tie2) and their ligands, the angiopoietins (Ang-1, Ang-2, Ang-3 and Ang-4), play a key role during the late phase of angiogenesis and are responsible for the maturation of newly formed vascular structures. In patients with ALD, concentrations of Ang-2 and VEGF-A were found to be increased relative to controls. It has also been observed that alcohol induces angiogenesis via platelet endothelial cell adhesion molecule-1 (89). This insight may contribute to the development of new anti-angiogenic treatment strategies.

\section{Fibrosis}

The course from chronic liver disease to cirrhosis is complex. It is modulated by the influence of various disease-specific, host-specific, and environmental factors. The development of liver fibrosis in alcoholics has been linked to oxidation of ethanol to the highly reactive compound acetaldehyde. After alcohol consumption, acetaldehyde stimulates not only type IV but also type I collagen synthesis and gene transcription in cultured rat and human HSCs through the activation of protein kinase $C$ (90). Liver fibrosis is a dynamic process that results from an imbalance between the production and dissolution of ECM. This again depends on the balance between matrix metalloproteinases (MMPs) and tissue inhibitors of matrix metalloproteinases (TIMPs). The increase in ECM is controlled by MMPs (MMP-1, MMP-2, MMP-8 and MMP-13), while the progression of fibrosis is correlated with an increase in TIMPs (TIMP-1 and TIMP-2) (91) (Fig. 5). A critical event in liver fibrogenesis is that ECM is a dynamic structure and even advanced fibrosis may be reversible. Multiple interactions between ECM, HSCs and immune cells have been identified. These findings have advanced the understanding of 
Table I. Potential future treatments for alcoholic liver disease.

\begin{tabular}{ll}
\hline Target & \multicolumn{1}{c}{ Medication } \\
\hline Microbiota & $\begin{array}{l}\text { Antibiotics } \\
\text { Prebiotics and probiotics } \\
\text { Blockade of LPS } \\
\text { Immune modulation } \\
\text { Inflammation }\end{array}$ \\
& $\begin{array}{l}\text { Chemokines (CCL20 inhibition) } \\
\text { Inhibition of IL-8, IL-17 } \\
\text { Recombinant IL-6, IL-10 } \\
\text { TNF- } \alpha \text { superfamily receptor } \\
\text { modulation (Y-40138) } \\
\text { Blockade of inflammasome activation } \\
\text { Blockade of angiogenesis }\end{array}$ \\
\hline
\end{tabular}

LPS, lipopolysaccharide; TNF- $\alpha$, tumor necrosis factor- $\alpha$.

the pathogenesis of liver inflammation and liver fibrosis and present opportunities for novel therapeutic approaches for the management of ALD and liver fibrosis.

\section{Treatment for ALD}

Abstinence from alcohol is the essential treatment for ALD (92). However, in most patients with ALD, abstinence is difficult to maintain. On the other hand, there is little pharmacological treatment for ALD. Thus, there is an urgent need to develop novel therapeutic interventions. There are many animal models of ALD, all having limits when it comes to mimicking human ALD. In the clinical setting, AH and alcoholic liver cirrhosis have identifiable symptoms and receive treatment. Patients with severe AH have a high mortality rate, approximately $50 \%$, and those who survive have a $70 \%$ probability of developing liver cirrhosis. Nutrition supplementation is necessary for patients with $\mathrm{AH}$ because of the prevalence of malnutrition. Corticosteroids and pentoxifylline are used in the treatment of $\mathrm{AH}$, both aiming to reduce inflammatory conditions. Corticosteroids reduce cytokine production through transcriptional regulation, and pentoxifylline has a similar effect through the inhibition of phosphodiesterases. These two agents have relatively strong side effects; thus, it is mainly used for severe $\mathrm{AH}$. On the other hand, probiotics are effective in ALD. Lactobacillus reduced endotoxemia and improved liver damage in a rat ALD model (93). Moreover, some clinical studies indicate the effectiveness of probiotics combined with antibiotic treatment. Rifaximin, a non-absorbable antibiotic that alters the gut microbiota, is efficacious in the treatment of hepatic encephalopathy and could have a role in modulating ALD (94). Inhibition of LPS-induced TLR4 or TNF- $\alpha$ signaling has been suggested as a target for novel therapies (95). It is suggested that blockade of angiogenesis could be a promising therapeutic option in patients with advanced fibrosis. Determination of proangiogenic factors may be a useful non-invasive approach in the follow-up of liver fibrosis progression and response to therapy. The main event in fibrogenesis appears to be the activation of HSCs, which indicates multiple potential sites for therapeutic interventions. Anti-angiogenic therapy may be promising in the prevention of fibrosis in chronic liver disease, however, it should be well balanced since an excessive blockage may prevent wound healing response. Specific, effective and safe antifibrotic therapies have not yet been developed that can mediate the progression of hepatic fibrogenesis.

\section{Future therapies for ALD}

As discussed in this review, future treatment strategies for ALD are summarized in Table I. Currently, the medical management of ALD is limited to steroids. Use of steroids can be associated with significant adverse reactions, such as infection and bone fractures. In addition, the long-term benefit of steroids remains to be established. Targeting gut microbes and their products, targeting hepatic inflammation and fibrosis, and immune modulation, help improve liver regeneration. These are the most promising areas for research and future clinical trials should focus on these areas in developing new therapies in the treatment for ALD.

\section{Conclusion}

Alcohol is one of the most common causes of chronic liver diseases worldwide (93). In the development of ALD or alcoholic liver cirrhosis, various factors, such as inflammation, oxidative stress, innate immunity, angiogenesis, or fibrosis, are important. Inflammatory cytokines, such as TNF- $\alpha$, play an important role in ALD. The progression of alcohol-induced liver injury involves immune cells and hepatocytes through the release of cytokines or chemokines. Kupffer cells play an important role in early-stage ALD, producing TNF- $\alpha$ through TLR4. In the current understanding of the pathogenesis of ALD, TNF- $\alpha$ appears to be a key to developing new approaches for its treatment. In contrast, ECM plays a key role in liver fibrogenesis, and multiple interactions between ECM, HSCs, and endothelial cells have been identified. Activation of HSCs is the central event in fibrogenesis, and TGF- $\beta$ is a key to developing new approaches for its treatment. The treatment of ALD has advanced only little after the introduction of corticosteroid therapy. The development of targeted therapies for ALD and alcoholic liver cirrhosis are hampered by poor knowledge of the molecular mechanisms involved in its development, particularly in humans and by the perception that it is an addictive and a self-inflicting disease. We propose that further reseach is warranted to increase the understanding of the pathogenesis of liver inflammation and fibrosis to discover novel therapeutic agents for patients with ALD.

\section{References}

1. Teli MR, Day CP, Burt AD, Bennett MK and James OF: Determinants of progression to cirrhosis or fibrosis in pure alcoholic fatty liver. Lancet 346: 987-990, 1995.

2. Lefkowitch JH: Morphology of alcoholic liver disease. Clin Liver Dis 9: 37-53, 2005.

3. Cojocariu CE, Trifan AV, Girleanu I and Stanciu C: Alcoholic liver disease - epidemiology and risk factors. Rev Med Chir Soc Med Nat Iasi 118: 910-917, 2014.

4. Stickel F: Alcoholic cirrhosis and hepatocellular carcinoma. Adv Exp Med Biol 815: 113-130, 2015. 
5. Browning JD and Horton JD: Molecular mediators of hepatic steatosis and liver injury. J Clin Invest 114: 147-152, 2004.

6. MacSween RN and Burt AD: Histologic spectrum of alcoholic liver disease. Semin Liver Dis 6: 221-232, 1986.

7. Haber PS, Warner R, Seth D, Gorrell MD and McCaughan GW: Pathogenesis and management of alcoholic hepatitis. J Gastroenterol Hepatol 18: 1332-1344, 2003

8. Tsujimoto T, Kuriyama S, Yamazaki M, Nakatani Y, Okuda H, Yoshiji $\mathrm{H}$ and Fukui $\mathrm{H}$ : Augmented hepatocellular carcinoma progression and depressed Kupffer cell activity in rat cirrhotic livers. Int J Oncol 18: 41-47, 2001.

9. Kitazawa T, Nakatani Y, Fujimoto M, Tamura N, Uemura M and Fukui $\mathrm{H}$ : The production of tumor necrosis factor-alpha by macrophages in rats with acute alcohol loading. Alcohol Clin Exp Res 27 (Suppl 8): 72S-75S, 2003

10. Rao RK, Seth A and Sheth P: Recent advances in alcoholic liver disease I. Role of intestinal permeability and endotoxemia in alcoholic liver disease. Am J Physiol Gastrointest Liver Physiol 286: G881-G884, 2004.

11. Canbay A,Feldstein AE, Higuchi H, Werneburg N, Grambihler A, Bronk SF and Gores GJ: Kupffer cell engulfment of apoptotic bodies stimulates death ligand and cytokine expression. Hepatology 38: 1188-1198, 2003

12. McClain CJ, Song Z, Barve SS, Hill DB and Deaciuc I: Recent advances in alcoholic liver disease. IV. Dysregulated cytokine metabolism in alcoholic liver disease. Am J Physiol Gastrointest Liver Physiol 287: G497-G502, 2004.

13. Gao B: Cytokines, STATs and liver disease. Cell Mol Immunol 2 92-100, 2005.

14. Garcin F, Lau You Hin G, Cote J, Radouco-Thomas S, Chawla S and Radouco-Thomas C: Aldehyde dehydrogenase in Drosophila: developmental and functional aspects. Alcohol 2: 85-89, 1985.

15. Lieber CS and DeCarli LM: The role of the hepatic microsomal ethanol oxidizing system (MEOS) for ethanol metabolism in vivo. J Pharmacol Exp Ther 181: 279-287, 1972.

16. Neve EP and Ingelman-Sundberg M: Molecular basis for the transport of cytochrome P450 2E1 to the plasma membrane. J Biol Chem 275: 17130-17135, 2000.

17. Lieber CS: Metabolic consequences of ethanol. Endocrinologist 4: 127-139, 1994

18. Bilzer M, Roggel F and Gerbes AL: Role of Kupffer cells in host defense and liver disease. Liver Int 26: 1175-1186, 2006.

19. Diehl AM: Recent events in alcoholic liver disease V. Effects of ethanol on liver regeneration. Am J Physiol Gastrointest Liver Physiol 288: G1-G6, 2005.

20. Hansen J, Cherwitz DL and Allen JI: The role of tumor necrosis factor-alpha in acute endotoxin-induced hepatotoxicity in ethanol-fed rats. Hepatology 20: 461-474, 1994.

21. Aldred A and Nagy LE: Ethanol dissociates hormone-stimulated cAMP production from inhibition of TNF-alpha production in rat Kupffer cells. Am J Physiol 276: G98-G106, 1999.

22. Kawaratani H, Tsujimoto T, Kitazawa T, Kitade M, Yoshiji H, Uemura $M$ and Fukui $H$ : Innate immune reactivity of the liver in rats fed a choline-deficient L-amino-acid-defined diet. World J Gastroenterol 14: 6655-6661, 2008.

23. Crespo J, Cayon A, Fernandez-Gil P, Hernandez-Guerra M, Mayorga M, Dominguez-Diez A, Fernandez-Escalante JC and Pons-Romero F: Gene expression of tumor necrosis factor alpha and TNF-receptors, p55 and p75, in nonalcoholic steatohepatitis patients. Hepatology 34: 1158-1163, 2001.

24. Tilg H, Jalan R, Kaser A, Davies NA, Offner FA, Hodges SJ, Ludwiczek O, Shawcross D, Zoller H, Alisa A, et al: Anti-tumor necrosis factor-alpha monoclonal antibody therapy in severe alcoholic hepatitis. J Hepatol 38: 419-425, 2003.

25. Akriviadis E, Botla R, Briggs W, Han S, Reynolds T and Shakil O: Pentoxifylline improves short-term survival in severe acute alcoholic hepatitis: a double-blind, placebo-controlled trial. Gastroenterology 119: 1637-1648, 2000.

26. Iimuro Y, Gallucci RM, Luster MI, Kono H and Thurman RG: Antibodies to tumor necrosis factor alfa attenuate hepatic necrosis and inflammation caused by chronic exposure to ethanol in the rat. Hepatology 26: 1530-1537, 1997.

27. Kawaratani H, Tsujimoto T, Kitazawa T, Yoshiji H, Uemura M and Fukui H: Therapeutic effects of cytokine modulator Y-40138 in the rat alcoholic liver disease model. J Gastroenterol Hepatol 26: 775-783, 2011.

28. Hong F, Kim WH, Tian Z, Jaruga B, Ishac E, Shen X and Gao B: Elevated interleukin-6 during ethanol consumption acts as a potential endogenous protective cytokine against ethanol-induced apoptosis in the liver: involvement of induction of Bcl-2 and Bcl-x(L) proteins. Oncogene 21: 32-43, 2002.
29. Mathurin P,Deng QG, Keshavarzian A, Choudhary S,Holmes EW and Tsukamoto $\mathrm{H}$ : Exacerbation of alcoholic liver injury by enteral endotoxin in rats. Hepatology 32: 1008-1017, 2000.

30. Hawrylowicz CM and O'Garra A: Potential role of interleukin-10-secreting regulatory T cells in allergy and asthma. Nat Rev Immunol 5: 271-283, 2005.

31. Louis H, Le Moine O, Goldman M and Deviere J: Modulation of liver injury by interleukin-10. Acta Gastroenterol Belg 66: $7-14,2003$.

32. Latvala J, Hietala J, Koivisto H, Jarvi K, Anttila P and Niemela O: Immune responses to ethanol metabolites and cytokine profiles differentiate alcoholics with or without liver disease. Am J Gastroenterol 100: 1303-1310, 2005.

33. Zhang X, Tachibana S, Wang H, Hisada M, Williams GM, Gao B and Sun Z: Interleukin-6 is an important mediator for mitochondrial DNA repair after alcoholic liver injury in mice. Hepatology 52: 2137-2147, 2010.

34. Rabe B, Chalaris A, May U, Waetzig GH, Seegert D, Williams AS, Jones SA, Rose-John S and Scheller J: Transgenic blockade of interleukin 6 transsignaling abrogates inflammation. Blood 111: 1021-1028, 2008.

35. Miller AM, Wang H, Bertola A, Park O, Horiguchi N, Ki SH, Yin S, Lafdil $\mathrm{F}$ and Gao B: Inflammation-associated interleukin-6/signal transducer and activator of transcription 3 activation ameliorates alcoholic and nonalcoholic fatty liver diseases in interleukin10-deficient mice. Hepatology 54: 846-856, 2011.

36. Jura J, Wegrzyn P, Korostyński M, Guzik K, OczkoWojciechowska M, Jarzab M, Kowalska M, Piechota M, Przewłocki R and Koj A: Identification of interleukin-1 and interleukin-6-responsive genes in human monocyte-derived macrophages using microarrays. Biochim Biophys Acta 1779: 383-389, 2008

37. Acosta-Rodriguez EV, Napolitani G, Lanzavecchia A and Sallusto F: Interleukins 1beta and 6 but not transforming growth factor-beta are essential for the differentiation of interleukin 17-producing human Thelper cells. Nat Immunol 8: 942-949, 2007.

38. Weaver CT, Hatton RD, Mangan PR and Harrington LE: IL-17 family cytokines and the expanding diversity of effector T cell lineages. Annu Rev Immunol 25: 821-852, 2007.

39. Lafdil F, Miller AM, Ki SH and Gao B: Th17 cells and their associated cytokines in liver diseases. Cell Mol Immunol 7: 250-254, 2010

40. Lemmers A, Moreno C, Gustot T, Marechal R, Degre D, Demetter P, de Nadai P, Geerts A, Quertinmont E, Vercruysse V, et al: The interleukin-17 pathway is involved in human alcoholic liver disease. Hepatology 49: 646-657, 2009.

41. Nanji AA, Zhao S, Sadrzadeh SM, Dannenberg AJ, Tahan SR and Waxman DJ: Markedly enhanced cytochrome P450 2E1 induction and lipid peroxidation is associated with severe liver injury in fish oil-ethanol-fed rats. Alcohol Clin Exp Res 18: 1280-1285, 1994

42. Ki SH, Park O, Zheng M, Morales-Ibanez O, Kolls JK, Bataller R and Gao B: Interleukin-22 treatment ameliorates alcoholic liver injury in a murine model of chronic-binge ethanol feeding: role of signal transducer and activator of transcription 3. Hepatology 52: 1291-1300, 2010

43. Dominguez M, Miquel R, Colmenero J, Moreno M, Garcia-Pagan JC, Bosch J, Arroyo V, Gines P, Caballeria J and Bataller R: Hepatic expression of CXC chemokines predicts portal hypertension and survival in patients with alcoholic hepatitis. Gastroenterology 136: 1639-1650, 2009.

44. Simpson KJ, Henderson NC, Bone-Larson CL, Lukacs NW, Hogaboam CM and Kunkel SL: Chemokines in the pathogenesis of liver disease: so many players with poorly defined roles. Clin Sci (Lond) 104: 47-63, 2003.

45. Jiang Y, Beller DI, Frendl G and Graves DT: Monocyte chemoattractant protein-1 regulates adhesion molecule expression and cytokine production in human monocytes. J Immunol 148: 2423-2428, 1992

46. Fisher NC, Neil DA, Williams A and Adams DH: Serum concentrations and peripheral secretion of the beta chemokines monocyte chemoattractant protein 1 and macrophage inflammatory protein lalpha in alcoholic liver disease. Gut 45 : 416-420, 1999

47. Lu B, Rutledge BJ, Gu L, Fiorillo J, Lukacs NW, Kunkel SL, North R, Gerard C and Rollins BJ: Abnormalities in monocyte recruitment and cytokine expression in monocyte chemoattractant protein 1-deficient mice. J Exp Med 187: 601-608, 1998.

48. Mandrekar P, Ambade A, Lim A, Szabo G and Catalano D An essential role for monocyte chemoattractant protein-1 in alcoholic liver injury: regulation of proinflammatory cytokines and hepatic steatosis in mice. Hepatology 54: 2185-2197, 2011. 
49. Sahin $\mathrm{H}$ and Wasmuth HE: Chemokines in tissue fibrosis. Biochim Biophys Acta 1832: 1041-1048, 2013.

50. Strieter RM, Burdick MD, Gomperts BN, Belperio JA and Keane MP: CXC chemokines in angiogenesis. Cytokine Growth Factor Rev 16: 593-609, 2005.

51. Alfonso-Loeches S, Ureña-Peralta JR, Morillo-Bargues MJ, Oliver-De La Cruz J and Guerri C: Role of mitochondria ROS generation in ethanol-induced NLRP3 inflammasome activation and cell death in astroglial cells. Front Cell Neurosci 8: 216, 2014.

52. Szabo G and Csak T: Inflammasomes in liver diseases. J Hepatol 57: 642-654, 2012.

53. Petrasek J, Iracheta-Vellve A, Saha B, Satishchandran A, Kodys K, Fitzgerald KA, Kurt-Jones EA and Szabo G: Metabolic danger signals, uric acid and ATP, mediate inflammatory cross-talk between hepatocytes and immune cells in alcoholic liver disease. J Leukoc Biol 98: 249-256, 2015.

54. Petrasek J, Bala S, Csak T, Lippai D, Kodys K, Menashy V, Barrieau M, Min SY, Kurt-Jones EA and Szabo G: IL-1 receptor antagonist ameliorates inflammasome-dependent alcoholic steatohepatitis in mice. J Clin Invest 122: 3476-3489, 2012.

55. Zhang Q, Raoof M, Chen Y, Sumi Y, Sursal T, Junger W, Brohi K, Itagaki $\mathrm{K}$ and Hauser CJ: Circulating mitochondrial DAMPs cause inflammatory responses to injury. Nature 464 104-107, 2010.

56. Akira S, Uematsu S and Takeuchi O: Pathogen recognition and innate immunity. Cell 124: 783-801, 2006.

57. Medzhitov R, Preston-Hurlburt P and Janeway CA Jr: A human homologue of the Drosophila Toll protein signals activation of adaptive immunity. Nature 388: 394-397, 1997.

58. Yamamoto M, Sato S, Hemmi H, Hoshino K, Kaisho T, Sanjo H, Takeuchi O, Sugiyama M, Okabe M, Takeda K, et al: Role of adaptor TRIF in the MyD88-independent toll-like receptor signaling pathway. Science 301: 640-643, 2003.

59. Petrasek J, Mandrekar P and Szabo G: Toll-like receptors in the pathogenesis of alcoholic liver disease. Gastroenterol Res Pract 2010: 710381, 2010

60. Szabo G, Mandrekar P, Petrasek J and Catalano D: The unfolding web of innate immune dysregulation in alcoholic liver injury. Alcohol Clin Exp Res 35: 782-786, 2011.

61. Yin M, Bradford BU, Wheeler MD, Uesugi T, Froh M, Goyert SM and Thurman RG: Reduced early alcohol-induced liver injury in CD14-deficient mice. J Immunol 166: 4737-4742, 2001.

62. Paik YH, Schwabe RF, Bataller R, Russo MP, Jobin C and Brenner DA: Toll-like receptor 4 mediates inflammatory signaling by bacterial lipopolysaccharide in human hepatic stellate cells. Hepatology 37: 1043-1055, 2003.

63. Fujimoto M, Uemura M, Nakatani Y, Tsujita S, Hoppo K Tamagawa T, Kitano H, Kikukawa M, Ann T, Ishii Y, et al: Plasma endotoxin and serum cytokine levels in patients with alcoholic hepatitis: relation to severity of liver disturbance Alcohol Clin Exp Res 24 (Suppl 4): 48S-54S, 2000.

64. Fukui H, Brauner B, Bode JC and Bode C: Plasma endotoxin concentrations in patients with alcoholic and non-alcoholic liver disease: reevaluation with an improved chromogenic assay. J Hepatol 12: 162-169, 1991.

65. Gustot T, Lemmers A, Moreno C, Nagy N, Quertinmont E, Nicaise $C$, Franchimont $\mathrm{D}$, Louis $\mathrm{H}$, Devière $\mathrm{J}$ and Le Moine $\mathrm{O}$ : Differential liver sensitization to toll-like receptor pathways in mice with alcoholic fatty liver. Hepatology 43: 989-1000, 2006.

66. MandrekarP, Catalano D, White B and Szabo G: Moderate alcohol intake in humans attenuates monocyte inflammatory responses: inhibition of nuclear regulatory factor kappa $B$ and induction of interleukin 10. Alcohol Clin Exp Res 30: 135-139, 2006

67. Hartmann P, Seebauer CT and Schnabl B: Alcoholic liver disease: the gut microbiome and liver cross talk. Alcohol Clin Exp Res 39: 763-775, 2015.

68. Keshavarzian A, Holmes EW, Patel M, Iber F, Fields JZ and Pethkar S: Leaky gut in alcoholic cirrhosis: a possible mechanism for alcohol-induced liver damage. Am J Gastroenterol 94: 200-207, 1999

69. Bala S, Marcos M, Kodys K, Csak T, Catalano D, Mandrekar P and Szabo G: Up-regulation of microRNA-155 in macrophages contributes to increased tumor necrosis factor $\alpha$ (TNF $\alpha$ ) production via increased mRNA half-life in alcoholic liver disease. J Biol Chem 286: 1436-1444, 2011.

70. Kavanaugh MJ, Clark C, Goto M, Kovacs EJ, Gamelli RL, Sayeed MM and Choudhry MA: Effect of acute alcohol ingestion prior to burn injury on intestinal bacterial growth and barrier function. Burns 31: 290-296, 2005.
71. Thakur V, McMullen MR, Pritchard MT and Nagy LE: Regulation of macrophage activation in alcoholic liver disease. J Gastroenterol Hepatol 22 (Suppl 1): S53-S56, 2007.

72. Rao R: Endotoxemia and gut barrier dysfunction in alcoholic liver disease. Hepatology 50: 638-644, 2009.

73. Yan AW, Fouts DE, Brandl J, Stärkel P, Torralba M, Schott E, Tsukamoto H, Nelson KE, Brenner DA and Schnabl B: Enteric dysbiosis associated with a mouse model of alcoholic liver disease. Hepatology 53: 96-105, 2011.

74. Bull-Otterson L, Feng W, Kirpich I, Wang Y, Qin X, Liu Y, Gobejishvili L, Joshi-Barve S, Ayvaz T, Petrosino J, et al: Metagenomic analyses of alcohol induced pathogenic alterations in the intestinal microbiome and the effect of Lactobacillus rhamnosus GG treatment. PLoS One 8: e53028, 2013.

75. Forsyth CB, Farhadi A, Jakate SM, Tang Y, Shaikh M and Keshavarzian A: Lactobacillus GG treatment ameliorates alcohol-induced intestinal oxidative stress, gut leakiness, and liver injury in a rat model of alcoholic steatohepatitis. Alcohol 43: 163-172, 2009

76. Gratz SW, Mykkanen H and El-Nezami HS: Probiotics and gut health: a special focus on liver diseases. World J Gastroenterol 16 : 403-410, 2010.

77. Choudhry MA, Fazal N, Goto M, Gamelli RL and Sayeed MM: Gut-associated lymphoid $\mathrm{T}$ cell suppression enhances bacterial translocation in alcohol and burn injury. Am J Physiol Gastrointest Liver Physiol 282: G937-G947, 2002.

78. Szabo G and Bala S: Alcoholic liver disease and the gut-liver axis. World J Gastroenterol 16: 1321-1329, 2010.

79. Hoek JB and Pastorino JG: Ethanol, oxidative stress, and cytokine-induced liver cell injury. Alcohol 27: 63-68, 2002.

80. Adachi Y, Moore LE, Bradford BU, Gao W and Thurman RG: Antibiotics prevent liver injury in rats following long-term exposure to ethanol. Gastroenterology 108: 218-224, 1995.

81. Semenza GL: Hypoxia-inducible factors in physiology and medicine. Cell 148: 399-408, 2012.

82. Carmeliet P and Jain RK: Molecular mechanisms and clinical applications of angiogenesis. Nature 473: 298-307, 2011.

83. Nath B and Szabo G: Alcohol-induced modulation of signaling pathways in liver parenchymal and nonparenchymal cells: implications for immunity. Semin Liver Dis 29: 166-177, 2009.

84. Valfrè di Bonzo L, Novo E, Cannito S, Busletta C, Paternostro C, Povero D and Parola M: Angiogenesis and liver fibrogenesis. Histol Histopathol 24: 1323-1341, 2009.

85. Novo E, Povero D, Busletta C, Paternostro C, di Bonzo LV, Cannito S, Compagnone A, Bandino A, Marra F Colombatto S,et al: The biphasic nature of hypoxia-induced directional migration of activated human hepatic stellate cells. J Pathol 226: 588-597, 2012.

86. Ciupińska-Kajor M, Hartleb M, Kajor M, Kukla M, Wyleżoł M, Lange D and Liszka L: Hepatic angiogenesis and fibrosis are common features in morbidly obese patients. Hepatol Int 7: 233-240, 2013.

87. Sanz-Cameno P, Trapero-Marugán M, Chaparro M, Jones EA and Moreno-Otero R: Angiogenesis: from chronic liver inflammation to hepatocellular carcinoma. J Oncol 2010: 272170, 2010

88. Marra F and Tacke F: Roles for chemokines in liver disease. Gastroenterology 147: 577-594.e1, 2014.

89. Raskopf E, Gonzalez Carmona MA, Van Cayzeele CJ, Strassburg C, Sauerbruch T and Schmitz V: Toxic damage increases angiogenesis and metastasis in fibrotic livers via PECAM-1. Biomed Res Int 2014: 712893, 2014.

90. Svegliati-Baroni G, Ridolfi F, Di Sario A, Saccomanno S, Bendia E, Benedetti A and Greenwel P: Intracellular signaling pathways involved in acetaldehyde-induced collagen and fibronectin gene expression in human hepatic stellate cells. Hepatology 33: 1130-1140, 2001.

91. Das SK and Vasudevan DM: Genesis of hepatic fibrosis and its biochemical markers. Scand J Clin Lab Invest 68: 260-269, 2008.

92. Gao B and Bataller R: Alcoholic liver disease: pathogenesis and new therapeutic targets. Gastroenterology 141: 1572-1585, 2011.

93. Nanji AA, Khettry U and Sadrzadeh SM: Lactobacillus feeding reduces endotoxemia and severity of experimental alcoholic liver (disease). Proc Soc Exp Biol Med 205: 243-247, 1994.

94. Bass NM, Mullen KD, Sanyal A, Poordad F, Neff G, Leevy CB, Sigal S, Sheikh MY, Beavers K, Frederick T, et al: Rifaximin treatment in hepatic encephalopathy. N Engl J Med 362: 1071-1081, 2010.

95. Mencin A, Kluwe J and Schwabe RF: Toll-like receptors as targets in chronic liver diseases. Gut 58: 704-720, 2009. 